\title{
Amazônia brasileira \\ e Patagônia argentina: \\ planos de desenvolvimento \\ e soberania nacional
}

GONZALO PÉREZ ÁLVAREZ ${ }^{I}$

\section{Introdução}

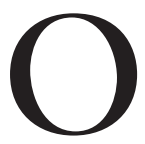

S PLANOS de desenvolvimento formulados pelo governo da Argentina para a Patagônia têm semelhanças evidentes com os projetos que formula o Estado federal do Brasil para a região da Amazônia. Em ambos se trata, no fundamental, de planos de desenvolvimento industrial subsidiados pelo Estado central.

A comparação entre as duas regiões se esclarece em suas características comuns de serem ricas em recursos naturais cobiçados por potências estrangeiras, serem definidas pelos seus governos nacionais como áreas "subdesenvolvidas" e contarem com uma baixa densidade populacional (valendo-se, em diversos informes estatais, da ideia de que se tratava de "regiões vazias").

Pretendemos gerar um debate a partir de algumas considerações da história da Patagônia, durante a fase de implementação dos planos de desenvolvimento (nos anos 1960), comparadas com os projetos similares promovidos pelo governo federal do Brasil. Também buscamos promover a reflexão necessária sobre os usos da noção de desenvolvimento, enfrentando a igualdade que se construíra entre esse conceito e o de crescimento.

A ideia de gerar "polos de desenvolvimento" propunha a criação de indústrias subsidiadas pelo Estado, que deviam se instalar nas regiões consideradas "marginais", por estar escassamente integradas ao mercado nacional. Na Argentina a Patagônia foi o centro de aplicação dessa proposta. Seus impulsores destacavam a necessidade de proteger dita região de seus recursos naturais, ao tempo que se tratava de descomprimir a agitação social de suas cidades tradicionais, em uma etapa de radicalização do movimento operário.

Um processo de industrialização impulsado pelo governo federal do Brasil é a Zona Franca de Manaus (capital do estado da Amazônia), onde se instalou um centro ensamblador de produtos eletrônicos, similar ao desenvolvido em Ushuaia (Província da Terra do Fogo, na Argentina). Os estudos e planos de desenvolvimento formulados pelo governo brasileiro para a Amazônia também 
fazem constante referência à necessidade de proteger uma região rica em recursos naturais para garantir a soberania nacional sobre esse território.

Queremos evidenciar a fonte autoritária de ambos os projetos, o peso que em sua criação teve a Doutrina de Segurança Nacional e o escasso rol que tiveram as populações das regiões para as quais foram ideados esses planos. Esta é uma investigação em fase inicial, de modo que este artículo apresenta aproximações e hipótese experimentais, cuja consolidação se realizará em futuros avances.

\section{Um contexto geral}

As políticas de promoção industrial para as regiões que analisamos se inscrevem num marco mais amplo que poderíamos denominar um "desenvolvimento genérico" (Perrén; Pérez Álvarez, 2011), expressão, ao mesmo tempo, do processo generalizado do colapso do consenso liberal que lhe seguiu à crise mundial de 1929-1930. Dita crise da economia mundial fez evidente a incapacidade dos princípios neoclássicos e a impossibilidade de que essa doutrina assegurasse o desenvolvimento dos países dependentes.

Avançava-se na necessidade de contar com um Estado ativo, que tivera ingerência na planificação econômica (Zambón, 2001). Hobsbawm (1999) destaca que o capitalismo havia consolidado uma estrutura baseada em um punhado de economias industriais e uma plêiade de países dependentes. $\mathrm{O}$ conceito de "países subdesenvolvidos" supunha que essa situação era superável; se eram aplicadas determinadas políticas se podiam eliminar as estruturas atrasadas e construir sociedades industriais e desenvolvidas. Fazia-se hegemônica a perspectiva de igualar a tríada crescimento-industrialização-desenvolvimento, sem praticamente pôr em debate suas diferenças e complexidades, e considerando que a industrialização eram sinônimos de desenvolvimento.

Para a América Latina essas ideias avançaram desde $1940 \mathrm{com}$ a tentativa da Comissão Econômica para América Latina (Cepal) de estruturar uma agenda comum para a região. Devia gerar-se a infraestrutura em transportes, energia e comunicações que permitissem o vínculo entre as regiões do país. Assim seria factível a plena ocupação do mesmo, e a utilização de todos os seus recursos naturais e humanos. Pelas suas extensas dimensões e sua complexa integração nacional, os casos do Brasil e da Argentina foram os que maiores estudos tiveram, e onde essas políticas adquiriram um peso mais relevante.

O esforço devia se concentrar na instalação de "polos de desenvolvimento", implementando em regiões periféricas atividades dinamizadoras, as quais emitiriam ondas concêntricas de crescimento que gerariam encadeamentos produtivos e assegurariam a plena conformação de um mercado nacional integrado, que romperiam com a situação de subdesenvolvimento (Perroux, 1955).

Para o caso do Brasil e da Argentina esses projetos tiveram um espaço-chave no qual ser desenvolvidos: aquelas áreas consideradas "subdesenvolvidas", incluídos no marco de países também comumente qualificados, ao mesmo tempo, como subdesenvolvidos. Essas regiões periféricas (em países que também são 
definidos como periféricos) estavam escassamente habitadas e pouco articuladas ao mercado capitalista nacional. Existiam outras regiões, em ambos os países, que para os anos 1950 e 1960 arrastavam essas condições. Porém, Amazônia e Patagônia se configuram como particularidades específicas, que levaram a que ambos os Estados nacionais os assimilaram como verdadeiros "laboratórios sociais", onde essas políticas seriam experimentadas.

$\mathrm{Na}$ sua condição comum de ser regiões com escassa densidade demográfica, extensos territórios, quase nula conexão com o mercado nacional e ausência de indústrias somaram-se outros elementos que consideramos serão chaves no contexto de governos de tradição autoritária que serão os principais impulsores das políticas de industrialização em ambas as regiões: sua riqueza em recursos naturais e a condição de tratar-se de territórios que, real ou simbolicamente, encontravam-se ameaçados em sua soberania nacional, seja por projetos de internalização (para a Amazônia), seja no caso da Patagônia pela cercania de potências estrangeiras (Inglaterra nas Ilhas Malvinas) e países limítrofes com disputas territoriais (Chile). ${ }^{1}$

Configurou-se um discurso que criava sentido na necessidade de integrar esses territórios ao mercado nacional, onde os aspectos econômicos, sociais e de segurança nacional se interconectavam. Ao mesmo tempo se construía um paradigma similar, que analisava esses territórios como espaços "vazios", "desertos" ou "desconhecidos". Os planos de promoção industrial se projetavam como continuidade da ocupação efetiva por parte do Estado: a industrialização era a prolongação da conquista militar por outros meios.

Em ambos os países se consolidou a imagem de que existiam na verdade dois Brasis, ou duas Argentinas: um dinâmico e aberto ao mundo; e o outro tradicional e antiquado (Lambert, $1976^{2}$ ). O imaginário futuro do país dependente como potência mundial (Perrén, 2008; Castro Lima, 2011; Contador, 2007) sustentava que não podiam ficar territórios isolados no marco desse "velho país". As regiões condenadas a um lugar marginal passavam a ser vistas como horizonte de progresso e potencial de expansão: eram territórios a conquistar (Healey, 2003). A tarefa "heroica" da conquista voltava a ser sustentada como paradigma da nova geração, induzida por esses governos autoritários; a industrialização seria a ferramenta-chave para fazer viáveis essas premissas.

Como dizíamos, Amazônia e Patagônia foram o laboratório ideal para provar este receituário, promovendo "polos de desenvolvimento" como ferramentas dinamizadoras do país. Esses polos deviam fortalecer as regiões débeis e atuar contra o "dualismo"; a realidade foi que seguiram funcionando a modo de enclaves, onde as regiões na que esses projetos se impunham pouco podiam decidir, e os programas impulsados eram dependentes de impulsos externos. A lógica com a que essas regiões tinham se incorporado ao mercado mundial voltava a se reproduzir nesse novo ciclo. ${ }^{3}$ 


\section{A Patagônia e seus projetos}

A Patagônia argentina ${ }^{4}$ se integra tardiamente à institucionalidade plena do Estado nacional argentino, sancionando-se sua conformação como províncias $^{5}$ num largo período que se inicia em 1955 e recém-finaliza em 1994 (com a transformação em província do território da Terra do Fogo e Ilhas do Atlântico Sul).

Sua incorporação plena ao Estado e ao mercado nacional se realiza no marco do impulso aos programas desenvolvimentista, em fins dos anos 1950 e início dos 1960 (Perrén; Pérez Álvarez, 2011). Não era uma coincidência que esses territórios estivessem atravessando seu processo de provincialização durante esse mesmo período: o Estado nacional buscava superar o atraso dessas "novas províncias", e o direito a eleger seus próprios governos e redigir suas constituições formava parte do câmbio que se promovia.

As províncias patagônicas foram parte do impulso desenvolvimentista, a partir dos projetos gerados desde o Estado nacional, que foi fortalecendo sua presença na região. Os discursos governamentais estiveram atravessados pelas noções de "integração" e "desenvolvimento", pretendendo a "conquista" do território nacional através de indústrias subsidiadas desde o Estado nacional e ratificando a necessidade de promover "polos de desenvolvimento" como meio para dinamizar ao conjunto do país. As complexas hidroelétricas em Neuquén, a criação de Jazidas Carboníferas Fiscais em Santa Cruz, a exploração da reserva mineral de Serra Grande em Rio Negro, o impulso à industrialização subsidiada em Chubut e Terra do Fogo, são evidências da concepção dominante relativo a como assegurar o crescimento da região.

Foi em meados de 1955 que o Congresso da Nação transformou em províncias a maioria dos territórios da Patagônia. O golpe militar que destituiu Juan Domingo Perón suspendeu a convocatória das eleições provinciais, embora não tenha gerado uma quebra marcada nas políticas desenvolvimentistas já iniciadas: de fato esse impulso foi aprofundado, reforçando-se o conteúdo de segurança e soberania nacional que sempre teria incorporada essa intenção de "ocupar e povoar" a Patagônia.

A economia patagônica era qualificada como "subdesenvolvida". Segundo o informe Altimir ${ }^{6}$ podia-se considerar uma estrutura produtiva característica de situações de subdesenvolvimento, não pelo produto por habitante, mas sim pela insuficiente diversificação de suas atividades produtivas e os escassos ingressos de sua população. Era, por isso e segundo o informe citado, mais uma região de desenvolvimento incipiente que um território classicamente subdesenvolvido, já que não se observavam "círculos viciosos de pobreza" nem superpopulação relativa.

A Patagônia, apesar de concentrar a maior parte da extração hidrocarbonífera, mantinha uma participação ínfima no produto bruto nacional. Sua estrutura produtiva dependia, em princípios dos ano 1960, de um punhado de atividades: agricultura de subsistência, agricultura de frutas e verduras no Rio 
Negro, produção de lã (já numa situação de estancamento) e extração de hidrocarburos. Em todos os casos praticamente não existia nenhum processamento local dessas matérias-primas.

A pecuária era, para a maior parte da superfície patagônica, a principal e quase única atividade produtiva. Em fins do século XIX a maior parte da Patagônia tinha sido integrada ao sistema econômico mundial como provedora de lã de ovelha, após receber o gado ovino expulso da Pampa Úmida pelo avanço dos cereais e do gado bovino (Bandieri, 2005). Esse processo produziu-se após a ocupação desses territórios, em torno de 1879, por parte do Estado argentino mediante a derrota dos povos indígenas que o habitavam. Dita campanha militar se denominou oficialmente "conquista do deserto" e foi dirigida por Julio Argentino Roca, quem logo governaria o país durante dois mandatos presidenciais, e é, até o presente, um dos principais próceres da história nacional.

Diversos fatores se conjugaram para que essa atividade começasse a perder dinamismo em meados do século XX: tendência descendente do preço da lã no mercado mundial desde os anos 1920, perda de importância do estreito de Magalhães pela abertura do canal de Panamá e o maior uso de fibras sintéticas. ${ }^{8}$

A Patagônia teve um início cedo, conforme se referem as políticas desenvolvimentistas, numa profunda relação com os conceitos de soberania nacional e segurança interna. Modificando a política prévia de assentar guarnições militares, as ditaduras militares aplicaram regimes de promoção industrial e atri-buíram recursos para montar uma infraestrutura que facilitara a ocupação civil das "novas províncias" (Ibarra, 1997).

A ideia de continuidade entre a função "conquistadora" que exerciam os quartéis militares e a tarefa que deviam cumprir as indústrias subvencionadas pelo Estado se refletiam em frases como a do secretário de Difusão e Turismo da ditadura que comandava o general Onganía, na sua visita à região: "As indústrias na Patagônia são como fortificações de Roca no deserto, ou seja, atalaias do progresso e da civilização, pontos de partida para o desenvolvimento". ${ }^{9}$

Criavam-se centros industriais que deviam irradiar o "progresso" às re-giões próximas ao polo originário, superando assim a dificuldade de um desenvolvimento homogêneo das regiões atrasadas. Essa formulação igualava industrialização, crescimento e desenvolvimento, e isso era possível em razão do aporte de um fator exógeno ${ }^{10}$ (especialmente a intervenção do Estado subsidiando inversões privadas).

Outro elemento para compreender o impulso de novos polos industriais na Argentina dos anos 1960 tem relação com a intenção de dividir a classe trabalhadora, isolando seus núcleos mais combativos. ${ }^{11}$ A matriz da Doutrina de Segurança Nacional considerava que na Argentina existia um "inimigo interno" o qual se deveria combater. Isso se refletia na intenção de fragmentar os trabalhadores, na constante referência à concepção de "soberania" e na intenção de povoar a Patagônia considerada uma região estratégica por seus recursos natu- 
rais (Gatica, 2013). Nesse marco, e como parte fundadora do projeto na Patagônia, conformou-se uma direção sindical local que sustentou uma prática de colaboração com o governo e as patronais, no marco do discurso comum acerca da necessidade de fortalecer o desenvolvimento regional. A Confederação Geral do Trabalho da região afirmava essa mesma ideia: "O desenvolvimento industrial é um desejo geral que os trabalhadores compartem inteiramente. Desenvolvimento industrial e desenvolvimento demográfico devem ir de mãos dadas". ${ }^{12}$

Podemos marcar o início formal do programa "desenvolvimentista" para a Patagônia em 1956, com a formulação do decreto-lei 10.991 da autodenominada "revolução libertadora", que eximia de impostos as importações ao sul do paralelo $42^{\circ} \mathrm{S}$. O impacto dessa política de franquias se concentrou ao nordeste de Chubut (a região ao sul do paralelo que se achava mais perto de Buenos Aires, uns $1400 \mathrm{~km}$ de distância $).{ }^{13}$

Nos primeiros anos da década de 1960 as franquias de importação foram substituídas pela isenção de impostos às indústrias que se instalassem na região. Através de sucessivas leis se deu impulso à produção de fibras têxteis sintéticas, projeto que impedia a articulação com a produção pecuarista tradicional na Patagônia (Ibarra, 1997). ${ }^{14}$ Durante o período 1955-1960 se instalaram em Chubut 34 plantas têxteis, quantidade que somente se compara com as que se instalariam entre 1970 e 1974. Desde 1970 o fluxo de radicações foi mais dinâmico, e entre 1970 e 1974 colocaram-se em funcionamento 35 plantas na província (Altimir, 1970). Ao mesmo tempo, muitas das velhas plantas foram fechando ante a nova competência e as constantes mudanças nas normativas legais. Por volta de 1974 calcula-se que existiam 45 empresas têxteis em produção, as que empregavam em torno de 4.300 pessoas (Beccaria, 1983).

Quando o impulso inicial à indústria têxtil estava se esgotando, somaram-se os chamados a povoamento da região, especialmente com a chegada das autoridades locais da ditadura iniciada em 1966 (autodenominada "revolução Argentina"). Como já vimos, a associação entre crescimento econômico e projeção demográfica não era privativa das autoridades. O secretário da União Industrial Patagônica assegurava que "as causas do subdesenvolvimento patagônico eram $[\ldots]$ a ausência do homem" e, por essa razão dizia que "levar população à Patagônia é pois a base". ${ }^{15}$

Assim foi que uma das consequências lógicas da instalação dessas indústrias foi o rápido crescimento demográfico. O departamento Rawson duplicou sua população entre 1960 e 1970, e voltou a duplicar entre 1970 e 1980. Trelew passou de 11.852 habitantes em 1960 para $38.664 \mathrm{em} \mathrm{1974.} \mathrm{A} \mathrm{população}$ no departamento Biedma, que se manteve quase sem mudanças entre $1945 \mathrm{e}$ 1970, triplicou entre 1970 e 1980, e voltou a duplicar-se ao redor de 1991. Esse crescimento esteve diretamente relacionado com a oferta trabalhista que gerou a industrialização subsidiada, refletindo também severos problemas urbanos, especialmente em torno a provisão de vivendas familiares. 
Em 1971 criou-se formalmente um Parque Industrial na cidade de Trelew. As tarefas de infraestrutura foram aportadas pelas diversas instâncias do Estado, sejam nacional, provincial, sejam municipal, realizando uma constante transferência de recursos aos empresários privados. Em 1973 a rama têxtil de Chubut ocupava o segundo lugar em âmbito nacional em várias áreas, ${ }^{16} \mathrm{e}$ em 1975 o nordeste da província passou a garantir mais de $70 \%$ da produção industrial provincial, em comparação com 36\% que concentravam em 1970. Ao mesmo tempo a indústria têxtil representava $65 \%$ da produção industrial da província (Gatica, 1998).

Também em 1971 adjudicou-se a ALUAR (Alumínio Argentino S.A.) o projeto de uma grande empresa produtora de alumínio primário, a única do seu tipo no país, que se instalaria na localidade de Porto Madryn. Como em Trelew, a inversão fundamental teve contribuição do Estado, realizando uma enorme transferência de fundos públicos a uma empresa privada. A avaliação do conjunto de inversões executadas para a instalação de ALUAR demonstrou que "o setor público investia mais de $84 \%$ do capital de ALUAR" (Rougier, 2011, p.356).

Um processo similar viveu o território da Terra do Fogo, no extremo sul da Argentina. Até avançada a década de 1960, sua única atividade econômica era a produção pecuária (ovinos para carne e lã). Por esses anos iniciou-se uma escassa operatória extrativa de petróleo e gás ao extremo norte da ilha (Gómez Lende, 2007). Isso se modificou a partir da década de 1970, quando sancionou-se a Lei n.19.640 estabelecendo um regime fiscal e aduaneiro especial.

Além de ter sofrido diversas modificações legais, os incentivos se basearam em promover a instalação de plantas ensambladoras de produtos eletrônicos, com grande semelhança ao processo impulsionado em Manaus pelo governo brasileiro (Mussi; Rodríguez Cybulski, 2011). A liberação das taxas alfandegárias ao comércio exterior e a isenção de tributos nacionais promoveram a instalação de indústrias que geraram o crescimento da população, que passou de 7 mil habitantes em 1960, para mais de 100 mil em 2001 (Schorr; Porcelli, 2014; Grigera, 2011).

Com a chegada da última ditadura (1976-1983), o discurso que procurava sustentar os subsídios voltou a se vincular com os chamados à segurança nacional. A hipótese de conflito com o Chile foi de importância fundamental: a necessidade de sustentar as indústrias como forma de garantir o assentamento da população era destacado como uma peça-chave no plano geopolítico.

Uma declaração da União Industrial Patagônica, com base em Chubut, marcava que seus propósitos não podiam estar "alheios aos objetivos políticos e estratégicos que a nação se propunha alcançar na região, aos imperativos da segurança nacional, nem a uma opção consciente dos bens materiais e espirituais a que nossa sociedade aspira". E terminava sua arenga tentando converter os interesses do setor industrial aos da Nação. Depois de tudo, rezava a declaração, 
“a industrialização é um movimento da sociedade como um todo; [...] não tem por finalidade fazer coisas, senão fazer um país". ${ }^{17}$

Os funcionários e industriais voltavam a construir a ideia da Patagônia como o deserto a ser povoado e conquistado. O relatório Altimir repete uma e outra vez a caracterização de Patagônia como território vazio. A qualificação de "espaço econômico vazio" reproduz a perspectiva fundadora desde a ocupação militar por parte do Estado, sob o discurso de que se estava conquistando um "deserto".

Por ocasião de visita à Patagônia para anunciar a construção da planta de alumínio, o ministro de Defesa, José Cáceres Monié, pronunciou por cadeia nacional um discurso que incluía conceitos como:

A quase um século desde o largo apogeu da larga e epopeia nacional que foi requisito para conquistar o deserto e afirmar a soberania sobre a Patagônia, os argentinos ainda não ocupamos este vasto âmbito que nos legara o esforço do Exército da Pátria, sob a condução visionária do general Julio Roca [...]. Encontramos na sua vastidão, o testemunho dos abnegados pioneiros que chegaram detrás das armas civilizadoras [... Eu creio que à Patagônia há de voltar-se a conquistar. Há de conquistar-se mediante um profundo desenvolvimento... ${ }^{18}$ Essa é a matriz constituinte dos projetos desenvolvimentistas para a Patagônia...

\section{A Amazônia brasileira}

As primeiras tentativas de ocupar o amplo território constituído pela Amazônia brasileira são retratadas no trabalho de Fonseca Gadelha (2002), quem recupera a obra de historiadores amazonenses, como Arthur Ferreira Reis e Samuel Belchimor. Quatro ideias nos parecem centrais nesse processo de ocupação: a da Amazônia como território vazio e desconhecido, como terra de fronteira, como terra a conquistar-se e como território sempre explorado desde "fora".

Geroncio Albuquerque Rocha (1992) mostra que a incorporação da Amazônia ao mercado mundial se realizou a partir de um estímulo externo à região e que essa lógica se manteve com os planos de promoção industrial. Citando Marcio Souza, afirma:

a Amazônia é uma região acostumada com o moderno [...] agricultura capitalista em 1760 com o Marquês de Pombal, economia capitalista exportadora em 1890 com a borracha, e estrutura industrial eletroeletrônica em 1970 com a Zona Franca de Manaus. Mas, por paradoxal que possa parecer, a região sempre se manteve isolada e à margem do contraditório processo de desenvolvimento do País. (Albuquerque Rocha, 1992, p.67-8)

Uma região acoplada à modernidade, porém desde fora, e com uma conexão estabelecida com o mercado mundial antes que com o nacional. As semelhanças com a história da Patagônia já começam a ser visíveis. E a configuração com um tipo de estrutura econômica que podemos qualificar como de "enclave" também parece ser evidente... 
Vários trabalhos sintetizam o processo de desenvolvimento da Zona Franca de Manaus, o caso mais paradigmático, e relativamente exitoso, entre os projetos planificados desde o Estado federal do Brasil, com o discurso de buscar o desenvolvimento da Amazônia.

Araujo Filho (2005) mostra que a Zona Franca de Manaus (ZFM) tem sua origem na Lei n.3.173, de 6 de julho de 1957, posteriormente regulamentada pelo Decreto n.47.757, de 2 de fevereiro de 1960. A ZFM tinha como objetivo inicial, o armazenamento, depósito, resguardo, conservação, recepção e exportação de mercadorias, artículos e produtos de qualquer natureza, provenientes do estrangeiro ou destinados ao consumo interno da Amazônia (Puga Ferreira; Botelho, 2014).

Esse projeto inicial não teve o impacto esperado, gerando unicamente um porto livre de impostos. Por isso a ZFM foi reestruturada dez anos mais tarde pelo Decreto-Lei n.288/67 (já durante o governo ditatorial), impulsionando a implementação de indústrias através da concessão de trinta anos de isenções impositivas em toda a Amazônia Ocidental (estados do Amazonas, Acre, Rondônia e Roraima). ${ }^{19} \mathrm{O}$ primeiro artigo de dito decreto afirma:

A Zona Franca de Manaus é uma área de livre comércio de importação e exportação e de incentivos fiscais especiais, estabelecida com a finalidade de criar, no interior da Amazônia, um centro industrial, comercial e agropecuário dotado de condições econômicas que permitam seu desenvolvimento. (Decreto-Lei n.288, Art. 1)

Como o leitor terá notado são claras as semelhanças durante o processo histórico com a industrialização subsidiada na Patagônia, tanto nos anos de instalação como na dinâmica: a aprovação de uma área livre de impostos a fins da década de 1950 que não logrou os objetivos de crescimento procurados, e que foi paulatinamente substituída por projetos de isenção impositiva para garantir a instalação de indústrias, a fins dos anos 1960 e princípios dos 1970. A chegada das indústrias seria a chave que iniciaria o processo de povoamento, consolidação da soberania nacional, crescimento, desenvolvimento e integração plena ao mercado nacional.

O modelo concedia incentivos a partir da isenção do imposto de importação e o de produtos industrializados (federais), o imposto de circulação de produtos e serviços (estaduais), e os impostos sobre serviços de qualquer índole (municipais). Como vemos, os três níveis de governo asseguravam esse programa, subsidiando as empresas que se instalavam ao seu amparo. Assim mesmo se garantiu a infraestrutura necessária para as indústrias, criando o Distrito Industrial em 1970.

O objetivo declarado era a integração dessa região ao resto do país. Porém a dimensão geopolítica, a partir das preocupações do Brasil para ocupar e controlar a Amazônia. Sem dúvidas essa preocupação ocupou um lugar central para o governo federal, especialmente na agenda da ditadura militar. ${ }^{20}$ 
Pinto (2002) sustenta que a política de segurança nacional relativa à Amazônia foi uma constante em crescimento durante os governos brasileiros desde a Segunda Guerra Mundial. Os nove mil quilômetros de fronteiras geraram uma obsessão pelo controle fronteiriço para garantir a soberania sobre o território. Essa seria a única maneira em que a Amazônia deixaria de ser o "desconhecido", para se transformar na inigualável fronteira de expansão da economia brasileira e a provedora de recursos naturais que fossem necessários em cada fase histórica.

A frágil soberania, vista na escassa população e na ausência de atividades econômicas de peso, aumentava o perigo de uma internacionalização, amparada em motivos ambientais (Araújo Filho, 2005). Por isso o Estado federal retomou o ideário de economistas como François Perroux, partidários da necessidade de um crescimento econômico localizado, que permitiria a rápida expansão da população e da ocupação territorial, mercê a irradiação que geraria o polo inicial (Kohlhepp, 2002).

O modelo da ZFM é implantado no marco das transformações na ordem econômica mundial e na política brasileira que se deu entre 1967 e 1973. O denominado "milagre econômico brasileiro" provocou um grande crescimento econômico: "o crescimento médio do PIB do 11,1\% entre 1968 e 1973" (Cysne, 1994, p.248). Werner Baer (1976, p.47) brinda alguns dados para dimensionar este processo nacional:

[...] a produção de aço cresceu de 2,8 milhões de toneladas em 1964 para 8,3 milhões em 1975; a capacidade instalada de energia elétrica expandiu-se de 6.840.000 megawatts para 19.500.500 no mesmo período; o cimento, de 5,6 para 17,9 milhões de toneladas; os veículos motorizados, de 184.000 para 930.000 e os automóveis de passageiros, de 98.000 para 524.000 .

Embora impressionantes num curto prazo, esses números não são tão significativos ao ser incorporados em uma mirada de médio prazo. Cysne (1994, p.232) mostra que:

do inicio de 1964 ao final de 1984, por tanto no período que cobre o ciclo de governos militares com um deslocamento temporal de três meses ditado pela disponibilidade de estatísticas das contas nacionais, o Brasil cresceu em média 6,15\% ao ano, contra os 7,12\% ao ano registrados entre 1948 e 1963.

Ainda mais complexa é a ideia de "milagre", quando contrapomos esses dados de crescimento com o repartição da riqueza gerada. Draibe (1994, p.300) mostra que $40 \%$ da população mais pobre conseguiam o $15,8 \%$ da renda em $1960,13,3 \%$ em 1970 e apenas $10,4 \%$ em 1980. Enquanto $10 \%$ mais ricos passavam de $34,6 \%$, a $42,3 \%$ e a $46,7 \%$, respectivamente. Paul Singer (1982), no seu clássico A crise do "milagre”, expõe o caráter concentrador da riqueza, favorável às grandes empresas de capital concentrado desse processo. $\mathrm{O}$ crescimento econômico não correspondia com o declamado desenvolvimento social. A artificial igualdade de crescimento e industrialização com desenvolvimento começava a demonstrar suas falências. ${ }^{21}$ 
Os problemas habitacionais para os imigrantes chegados a Manaus pelas ofertas de trabalho em expansão não demoraram aparecer (De Souza, 2003). Assim como nos casos da Patagônia, porém com maior aumento populacional, a instalação de indústrias transformou (poderíamos dizer que fez renascer) Manaus. Em 2010 essa cidade contava com uma população perto dos dois milhões de habitantes, multiplicando-se por dez à existente antes da ZFM (Puga Ferreira; Botelho, 2014).

A cidade, que até a ZFM era dependente do comércio com o interior do estado, ${ }^{22}$ adquiriu uma dimensão tal que o interior passou a depender dela, concentrando 90\% da economia amazonense (Puga Ferreira; Botelho, 2014). É o único município do estado com um índice de desenvolvimento humano considerado alto (Bomfim; Botelho, 2009). Isso num contexto em que nenhum chega a um padrão muito alto e a maioria está entre os parâmetros de baixo a muito baixo.

A população que chegava à cidade, na maioria, era proveniente do interior do estado do Amazonas, além de outros estados ao redor. Deu-se um processo similar ao patagônico, com o despovoamento do interior amazônico, e a concentração no centro urbano, com superpopulação em periferias pobres sem condições mínimas de infraestrutura urbana (serviços, transportes, educação e saúde, ver Salazar $(1985 ; 1992)$ ). Infraestrutura que o Estado havia garantido para as indústrias.

O acesso a moradia é até o presente um dos principais eixos do conflito social mais relevante (Farias de Moura; Schor; Aldemir de Oliveira, 2011). Apareceu a chamada "cidade flutuante", conjunto de vivendas sobre embarcações no rio Amazonas, que foram desalojadas (Salazar, 1985). Em diversas áreas surgiram ocupações irregulares, formando novos bairros (Pereira da Costa; Aldemir de Oliveira, 2007). As possessões de terras foram comuns durante a década de 1980, com organizações que impulsaram mais de 35 ocupações, de maneira formalmente ilegal, mas aceitas pelo Estado, que não oferecia outra solução para os trabalhadores (Batista Santos, 2009).

O trabalho coordenado por Luiz Felippe Wiedemann (1977), Brasil realidade e desenvolvimento, sintetiza a visão oficial que se construía sobre esse processo desde a ditadura militar que governou o Brasil entre 1964 e 1985. Trata-se de um escrito de mais de 500 páginas, que procura legitimar o governo militar, apresentando dados e projeções sobre a economia e a sociedade do Brasil. O trabalho é realizado por membros da Escola Superior de Guerra (ESG), o Ministério do Planejamento, a Fundação Getulio Vargas, professores universitários e jornalistas.

Ao analisar a Amazônia o relatório afirma que se trata de mais da metade do território brasileiro, que está “[...] coberto por impenetrável massa florestal, ainda completamente inexplorada e desconhecida. Os recursos da área humanizada asseguram para o Brasil uma capacidade imensa de desenvolvimento que hoje começa a se pronunciar" (Wiedemann, 1977, p.30). 
Esse enorme território "inexplorado e desconhecido" é a chave do desenvolvimento integral do Brasil. As características centrais das distintas áreas do país são assim sintetizadas: "O Centro sul: integralmente populoso e desenvolvido; o Nordeste: populoso e subdesenvolvido; a Amazônia: subpopulosa e subdesenvolvida" (ibidem, p.31).

A questão seria gerar as condições para promover o traslado do "excedente" populacional do Nordeste para a Amazônia, num processo apresentado como uma conquista heróica de um território enorme e desconhecido: "Anunciando em Manaus o Programa de Integração Nacional, dizia o Presidente Emílio Garrastazu Médici que 'o problema inicial da Amazônia é conhecê-la de verdade" (ibidem, p.133).

O trabalho sintetiza a perspectiva de desenvolvimento de que era tributária a ditadura brasileira: a instalação de indústrias faria possível o crescimento e este, ao mesmo tempo, o desenvolvimento integral, em sucessivos passos que continuariam a mesma evolução do processo "clássico" de industrialização europeia: "É importante por isso, considerar o processo de desenvolvimento industrial como um sinônimo de progresso econômico [...] o desenvolvimento industrial confunde-se com o próprio desenvolvimento econômico" (ibidem, p.251). Um dos expoentes dessa perspectiva mecanicista e a-histórica, W. W. Rostow, ${ }^{23}$ é citado em diversas seções como critério de autoridade. A ocupação da Amazônia se assemelha, como no caso da Patagônia, à conquista definitiva do território brasileiro. Ocupar esse "indomável” território significava: "Conquistar meio Brasil para os brasileiros" (ibidem, p.254), em "uma empolgante aventura, capaz de despertar a vocação de grandeza de todo um povo" (ibidem, p.252), levando assim a que "As políticas de integração nacional e de desenvolvimento [...] inspiradas que estão na realidade geopolítica brasileira, nos levarão em breves anos, à conquista definitiva de nosso território" (ibidem, p.489).

É importante sintetizar a transcendência da Escola Superior de Guerra na planificação desses projetos vinculados à concepção de segurança nacional no Brasil. Eliezer Oliveira (1976) explora esse organismo, formado em 1948, mas que adquire um novo rumo desde finais dos anos 1950. Ali modifica sua perspectiva de segurança nacional, passando dos possíveis enfrentamentos com "inimigos externos", à Doutrina de Segurança Nacional, cuja questão é enfrentar ao "inimigo interno": aqueles grupos que lutam por um câmbio social. Esse processo não se pode entender sem a referência concreta da luta de classes a nível internacional, centralmente aludimos à vitória vietnamita em Dien Bien Phu, 1954, e à revolução cubana, em 1959.

Construiu-se um absoluto acompanhamento aos Estados Unidos, como parte do bloqueio ocidental contra "o comunismo", entendido como um risco perigoso para o Brasil. Por isso o golpe militar de 1964 é qualificado como "preventivo" (Fernandes, 1975), sendo relativamente bem-sucedido nesse objetivo.

Para a ESG o combate contra o comunismo tornava chave a tarefa de ocu- 
par o espaço “vazio” a nível territorial (Oliveira, 1976). Toda atuação política devia se submeter ao planejamento, principal chave para impedir o progresso comunista. O sujeito central do projeto de desenvolvimento era, para eles, o capital estrangeiro, o único que contava com a capacidade de modernizar a economia brasileira.

Em contraste com a queda da promoção industrial no Chubut desde os anos 1990, e o estancamento da produção eletrônica na Terra do Fogo, a ZFM manteve uma continuidade e tem um auge produtivo atual que marca uma diferença com a industrialização subsidiada na Patagônia. Isso apesar do fato de que, durante essa década do fim de século, a liberalização do comércio ditada pelas políticas neoliberais também trouxe sérios problemas para a ZFM, causando o colapso de importantes elos da cadeia de produção de vários de seus produtos.

Uma das razões dessa continuidade é a permanência de subsídios relevantes para as empresas aí localizadas, ao contrário da Argentina, onde foram quase inteiramente eliminados. Na Patagônia, ademais, os custos laborais sempre foram um pouco mais altos que na região central da Argentina; isso levou ao cancelamento dos projetos quando não existiam incentivos estatais relevantes. Para a Amazônia, no entanto, o fornecimento de uma força de trabalho abundante ficou firme, com bons níveis de formação e sem custos mais elevados do que em outras regiões, fazendo que, em muitos casos, as empresas optem por manter métodos de produção mais antigos, de mão de obra intensiva (Puga Ferreira; Botelho, 2014).

Claramente um dos eixos do programa de implementação de indústrias em Manaus tem relação com o risco de perda da soberania do Brasil sobre a Amazônia. Como no caso da Patagônia, a ZFM se apresenta como antídoto contra esses perigos, a partir de promover a ocupação de uma região despovoada. Deveriam garantir-se meios de vida para promoção da migração massiva, originando os subsídios e a infraestrutura que assegurassem a rentabilidade das indústrias (Seráfico; Seráfico, 2005).

Porém, além disso, esse projeto integrou o discurso nacionalista-militar com o processo de transnacionalização do capital. O papel da ditadura foi construir as condições ótimas para a inversão capitalista no Brasil, rebaixando o valor da força de trabalho através do controle e repressão das organizações operárias. A promoção ao desenvolvimento industrial transnacional em Manaus foi parte desse processo.

A integração da Amazônia ao mercado nacional se realizou em um marco em que a economia do Brasil se submetia ainda mais à dominação imperial. Assim a Amazônia continuou sua relação mais direta com o mercado mundial, a partir da instalação de empresas multinacionais, que fizeram uso da mão de obra regional, da possibilidade de usufruir os subsídios estatais, e de aproveitar um mercado interno em crescimento e quase cativo.

Produziu-se uma articulação entre o que Seráfico e Seráfico (2005) deno- 
minam o "ordem mundial", o "ordem nacional" e o "ordem regional", num momento de transição de "um projeto de capitalismo nacional para outro de capitalismo associado e, no limite, de capitalismo transnacional, em que a dinâmica econômica e os centros decisórios estão fora do país" (Seráfico; Seráfico, 2005, p.108).

\section{Conclusões}

Pretendíamos pôr em debate as semelhanças entre os planos de desenvolvimento que Argentina e Brasil implementaram para duas amplas regiões de seu território a partir meados dos anos 1950, cujo impulso seria acentuado porém durante os anos 1960 e 1970.

Esse modelo, comumente conhecido como "polos de desenvolvimento", teve como matriz a reafirmação da importância da planificação do desenvolvimento econômico por parte dos Estados nacionais, a partir de crise da hegemonia do liberalismo clássico. O desenvolvimentismo punha ênfase na necessidade de um crescimento acelerado das economias nacionais, atraindo o ingresso de capitais de origem estrangeiro e promovendo a industrialização, chave do crescimento e do desenvolvimento.

Essa visão se misturava com a Doutrina de Segurança Nacional e o acompanhamento das classes dominantes e dos governos federais de ambos os países aos Estados Unidos, na sua luta contra o "comunismo". As referências das lutas anti-imperialistas em vários países do mundo e o crescente poder das classes subalternas dos países em questão geraram o aprofundamento do autoritarismo na Argentina e no Brasil.

Desde esses governos se planificarão esses programas. A Amazônia brasileira e a Patagônia argentina configuraram-se como laboratórios ideais para a experimentação desses modelos. Sua condição comum de ser regiões consideradas marginais e "subdesenvolvidas", com escassa densidade populacional, com grandes recursos naturais ainda sem explorar e onde a soberania nacional estava em perigo, configuravam um conjunto de traços em comum. Para promover a instalação das indústrias era necessário assegurar o lucro desses empreendimentos: isso era feito através da transferência de recursos estatais a capitais privados, em muitos casos estrangeiros.

Também devia garantir-se a provisão estável de força de trabalho, incentivando a migração de trabalhadores/as a essas "novas terras". Essa força de trabalho devia ser controlada e maleável, e tinha que apresentar um nível de agitação social menor às regiões centrais. Para ambos os casos, ao menos durante os primeiros anos dos projetos, a característica distintiva foi dada pela escassez de conflitos de grande importância, especialmente em contraste com a ativação operária que existia naqueles anos nas cidades industriais mais tradicionais.

As indústrias criariam o crescimento econômico e esse garantiria, ao mesmo tempo, o desenvolvimento integral da região e sua conexão plena com o mercado nacional. Assim se conseguiria a ansiada "integração nacional" e am- 
bos os países deixariam de estruturar-se em torno a um centro rico e periferias pobres.

Isso foi um fracasso. Se é complexo saber se os objetivos declamados eram os sinceramente pretendidos, podemos concluir que somente foram bem-sucedidos em conseguir o povoamento dos centros urbanos receptores da industrialização subsidiada. Porém esse crescimento deu-se graças ao despovoamento do interior rural, tanto do centro e do cordilheira da Patagônia como da área rural do estado do Amazonas. Foi assim destruído parte das capacidades produtivas preexistentes nessas regiões, atividades que, precisamente, não eram dependentes dos estímulos fiscais.

Foram construídos projetos que, paradoxalmente, importam mais do que exportam. Sendo ambos os projetos estimulados à custa de incentivos fiscais elevados (federais, estaduais e municipais), foram alimentados muito mais da relocalização de instalações industriais já existentes em outras regiões industrializadas, que de novos investimentos nos países, essencialmente no que diz respeito à produção de eletrônicos.

Os encadeamentos produtivos que deveriam se estabelecer a partir das "ondas concêntricas de desenvolvimento irradiadas pelo polo" (Perroux, 1955), nunca conseguiram ser construídos. Esses encadeamentos eram de fato inviáveis, por se tratar de projetos impostos desde fora, que utilizavam insumos importados e não podiam articular-se com as atividades tradicionais de cada região (Salazar, 1992). A condição de enclave das atividades econômicas nestas regiões, se viram acentuadas: "A periferia tornou-se mais dependente do centro, em nível nacional e internacional. Em vez de polos de crescimento com impulsos de desenvolvimento irradiantes, surgiram enclaves, mantidos artificialmente" (Kohlhepp, 2002, p.40).

Em uma estrutura de enclave as atividades produtivas que se realizam têm fraca ou nula articulação com os demais ramos e, por isso, um escasso efeito multiplicador sobre o conjunto da economia. A base de sua conformação está estabelecida por estímulos externos à região, já sejam contribuições do Estado ou a exportação do produto sem quase valor agregado.

Esses enclaves têm uma grande fragilidade por sua especialização extrema e pela dependência de fatores externos: qualquer mudança levará à queda. A permanência da situação de enclave para a Patagônia e para a Amazônia parece ser uma matriz evidente. Assim o demonstra a permanência de ciclos de auge e caída, a partir da demanda de algum recurso natural ou de um programa subsidiado pelo Estado.

A condição de enclave não apenas se observa na estrutura econômica, senão que se manifesta no plano das decisões políticas. $\mathrm{O}$ pôr-se em funcionamento desses projetos e as mudanças que sofreram ao longo dos anos tiveram escassa participação dos sujeitos locais; aqueles que habitavam os territórios que, segundo os governos federais, deviam ser conquistados pela onda industrialista. 
Os habitantes locais foram objeto desses projetos, e não sujeitos deles. No repetido sermão que se centrava em uma "conquista" definitiva desses territórios, essas populações passavam a ser alvo da ocupação, pelas forças do progresso. Como o vimos no caso argentino, agora as indústrias substituiriam os fuzis. Porém a dimensão militar e de ocupação de um território supostamente indomável, selvagem e desconhecido, seguia presente nos horizontes do imaginário construído.

A fonte autoritária desses projetos de desenvolvimento industrial, o peso fundamental da doutrina de segurança nacional e o escasso papel que tiveram as populações locais na criação desses programas são semelhanças que expõem a necessidade de seguir explorando essas matrizes compartidas, que formam parte da conformação geral do autoritarismo de ambos os países, da permanência de regiões favorecidas e empobrecidas, e das democracias restringidas que surgiram durante os anos 1980.

\section{Notas}

1 Sendo marcada a necessária nuance de que ambas as experiências foram também empuxadas por governos constitucionais, interessados em estabelecer uma política de desenvolvimento regional. Apesar dessa ênfase é óbvio que a ditadura militar brasileira (1964-1985) e a ditadura argentina (1966-1973 e 1976-1983) pegam nas suas agendas esses projetos, dando centralidade à sua relevância em termos de segurança nacional e deixando mais ao nível da retórica a chave para o desenvolvimento regional.

2 “[...] uma evoluída e outra arcaica, que podem ser muito diferentes e que tanto mais se diferenciam quanto a difusão do progresso técnico é mais rápida e menos geral; essa modalidade de atraso e de avanço cultural é habitualmente designada pelo nome de "sociedade dualista" (Lambert, 1976, p.66).

3 Tanto a Amazônia como a Patagônia são incorporadas ao mercado internacional como provedoras de bens primários, previamente à sua incorporação ao mercado nacional. Suas economias viveram, até as primeiras décadas do século XX, uma etapa de auge: no caso da Amazônia especialmente pela extração do látex, e na Patagônia, pela produção lanar e sua localização estratégica do estreito de Magalhães como única conexão navegável entre o oceano Atlântico e o Pacífico. A dependência de estímulos externos somado à ausência de encadeamentos produtivos próprios ao interior de cada região constituem um ciclo que parece se repetir uma e outra vez, logrando fases de auge enquanto o estímulo externo permanece, e caídas pronunciadas quando este deixa de existir. Os lucros obtidos em cada ciclo se externam, e por isso não são acumuladas na própria região.

4 Incluímos ali, de acordo com a divisão clássica em regiões da Argentina, as províncias de Neuquén, a Pampa, Rio Negro, Chubut, Santa Cruz e Terra do fogo. Neste trabalho o foco será a Patagônia “sul”, da qual faz parte Chubut, Santa Cruz e Terra do Fogo.

5 Até ali esses territórios eram considerados Territórios Nacionais, status jurídico que não lhes permitia eleger seus próprios governantes (o governador era eleito pelo presidente da nação), nem ditar suas leis. Juridicamente eram territórios dependentes do governo federal. 
6 Trata-se de uma exaustiva investigação oficial, publicada com o título de "Análise da economia de Chubut e de suas perspectivas de desenvolvimento" solicitada pelo governo de Chubut junto a organismos do governo nacional. Está dividido em três volumes, com mais de dois mil fólios, nos quais se planifica o desenvolvimento projetado dessa província em todas suas variáveis.

7 A operação ideológica de nomear como "deserto" as terras conquistadas procurava construir a noção de que essas não estavam habitadas ou bem, que aqueles que até então as habitavam não eram "civilizados”. A “conquista do deserto" seria o avanço da civilização sobre a barbárie, na teoria sarmientina. O duplo caráter da palavra deserto (como âmbito geográfico supostamente improdutivo e como espaço sem população) legitimava a ocupação militar dessas terras por parte do Estado nacional. A conquista militar realizou-se a sangue e fogo, com a formação de campos de concentração e a transformação de muitos indígenas (especialmente mulheres e crianças) em escravos das famílias endinheiradas (Delrio, 2005).

8 Como vemos em todos os casos, tratava-se de processos externos à região e que não dependiam de sua planificação produtiva local. Isso é especialmente claro no caso da lã, cujo preço sempre foi formado a nível internacional. Algo similar acontecia com a extração do látex na região amazônica.

9 Declarações de Rodolfo Baltiérrez, no Jornal Jornada, 21.9.1970, p.3.

10 Ver Benko e Lipietz (1994); Coraggio (1972). Para abordar os debates atuais sobre a(s) teoria(s) do desenvolvimento, ver Vidal e Guillén (2008); Aronskind (2001); Katz (2008) e Ornelas Delgado (2012).

11 Ver a hipótese de que esses projetos procuravam "desanimar" o trabalho industrial em áreas tradicionais, para descomprimir a agitação existente, em Schvarzer (1986).

12 Jornal Jornada, 16.6.1970, p.6.

13 Sub-região que definimos a partir dos departamentos administrativos de Rawson y Biedma, parte norte da província de Chubut. Foi a zona com maior desenvolvimento industrial, onde se encontram as cidades de Trelew, Rawson e Porto Madryn, que se constituíram como os centros receptores de inversão por serem as cidades mais próximas ao limite norte habilitado, expressando assim a lógica expectativa dos empresários privados de conseguir lucros em curto prazo, e não de "propender ao desenvolvimento da Patagônia”. A grande extensão patagônica seguia sumida na produção pecuarista ovina.

14 Esse autor explica que o projeto original propunha a instalação de um polo petroquímico na cidade de Comodoro Rivadavia (região produtora de petróleo), que devia produzir fibras sintéticas que processaria o polo de Trelew. Ao não se instrumentar o polo petroquímico, o parque industrial de Trelew se constituiu um enclave sem encadeamentos produtivos na região.

15 Jornal Jornada, 15.11.1969; p.2. Citado em Gatica et al. (2005, p.51). Num discurso muito semelhante, como vemos, ao clássico slogan de Alberdi: "governar é povoar".

16 Embora um segundo lugar muito distante do centro têxtil tradicional: Chubut ocupava o segundo lugar na produção de meias (15\%, contra $83 \%$ da área metropolitana), tecido de ponto ( $11 \%$ contra $81 \%)$ e fiado de fibras têxteis $(6,4 \%$ contra $76 \%)$. Dados de Cimillo (1985, p.12-13).

17 Jornal El Chubut, 2.9.1979, p. 7. 
18 Jornal El Chubut, 7.5.1971, p. 6.

19 Uma área de $2.185 .202,2 \mathrm{~km}^{2}$ que corresponde a 56,7\% da Região Norte e a $25,7 \%$ do território brasileiro.

20 Preocupação aproveitada pela extrema direita dentro da ditadura: "A dinâmica da candidatura Albuquerque Lima ocupa o espaço, até então vazio, do nacionalismo exacerbado pela ameaça da desnacionalização da Amazônia. A ação do ministro do Interior em defesa da região amazônica, estimulando, inclusive, através do Projeto Rondon, a interiorização de estudantes junto às populações periféricas carentes, respondia também às preocupações da jovem oficialidade" (Trindade, 1994, p.138).

21 Igualdade que já havia sido discutida por diversos intelectuais. Ver, por exemplo, o notável caso de Caio Prado Jr. (1959). Também Bispo (2003, p.42), sustenta a necessidade de diferenciar: “[...] desenvolvimento econômico de crescimento econômico. O primeiro constitui um processo de mudanças qualitativas na estrutura da economia que conduzem à melhoria do bem-estar das populações, enquanto o segundo tem conotação apenas quantitativa, traduzindo-se por uma expansão global da produção de bens e serviços à disposição de uma comunidade, sem reflexos sensíveis na distribuição de renda".

22 Era um centro comercial concentrador de produtos, especialmente de recursos naturais, de seu hinterland. Nesse sentido cumpria uma função similar à que tinha Trelew para com a província de Chubut, desde o começo do funcionamento do Trem Central Patagônico, em 1886, até a implantação do modelo de polo de desenvolvimento na década de 1960.

23 Assim sintetiza, cremos que corretamente, sua trajetória o portal Wikipedia: "economista estadunidense e político conhecido por sua oposição ao comunismo, crente na eficácia do capitalismo e da livre empresa. Conselheiro de Segurança Nacional do Presidente Lyndon Johnson" (disponível em: <http://es.wikipedia.org/wiki/Walter_ Whitman_Rostow>). Como vemos não se tratava de um "simples" economista, senão também um funcionário-chave do governo dos Estados Unidos na área de segurança.

\section{Referências}

ALBUQUERQUE ROCHA, G. Ai de ti, Amazônia. Estudos Avançados, São Paulo, v.6, n.15, p. 67-78, 1992.

ALTIMIR, O. Análisis de la economía del Chubut y de sus perspectivas de desarrollo, Tomo I, II y III. Rawson, Provincia del Chubut: Asesoría de Desarrollo, 1970.

ARAÚJO FILHO, G. Cooperação entre empresas no polo industrial de Manaus. Rio de Janeiro, 2005. Tese (Doutorado em Engenharia da Produção) - Universidade Federal do Rio de Janeiro. Rio de Janeiro, 2005.

ARONSKIND, R. ¿Más cerca o más lejos del desarrollo? Buenos Aires: Libros del Rojas/ Eudeba. 2001.

BAER, W. The brazilian growth and development experience: 1964-1975. In: ROETT, R. (Org.) Brazil in the seventies. Washington DC: Institute for Public Research, 1976.

BANDIERI, S. Historia de la Patagonia. Buenos Aires: Sudamericana, 2005. 
BATISTA SANTOS, C. Direito a moradia na cidade de Manaus. Ser Social 8, p.209235, 2009. Disponível em: <periodicos.unb.br/index.php/SER_Social/article/download $/ 45 / 38>$.

BECCARIA, L. (Dir.) El caso de la industria textil en Chubut. Buenos Aires: Banade, 1983.

BENKO, G.; LIPIETZ, A. Las regiones que ganan. Distritos y redes. Los nuevos paradigmas de la geografía económica. Valencia: Generalitat Valenciana, 1994.

BISPO, J. de S. Polo industrial exportador: desafios para o novo papel da Zona Franca de Manaus. Rio de Janeiro 2003. Tese (Mestrado) - Escola Brasileira de Administração Pública e de Empresas. Rio de Janeiro, 2003. Disponível em: <http:// bibliotecadigital.fgv.br/dspace/bitstream/handle/10438/3738/000320874. pdf? sequence $=1$ \&isAllowed $=\mathrm{y}>$.

BISPO, J. de S. Criação e distribuição de riqueza pela Zona Franca de Manaus. São Paulo, 2009. Tese (Doutorado) - Universidade de São Paulo. São Paulo, 2009. Disponível em: < www.teses.usp.br/teses $>$.

BOMFIM, R.; BOTELHO, L. Zona Franca de Manaus: condicionantes do futuro. Manaus: Valer, 2009.

BRASIL. Legislação Básica da Zona Franca de Manaus. São Paulo, Faculdade de Direito, USP, s. d.

CASTRO LIMA, S. de. Da substituição de importações ao Brasil potência: concepções do desenvolvimento 1964-1979. AURORA, ano V, n.7, jan. 2011. Disponível em: $<$ www.marilia.unesp.br/aurora>.

CIMILLO, E. Bloque textil: dinámica en la provincia del Chubut. 1973-1984. Buenos Aires: CFI-Cepal, 1985.

CONTADOR, V. Modelo econômico e projeto de nação-potencia: Brasil, 1964-1985. São Paulo, 2007. Tese (Doutorado) - Faculdade de Filosofia, Letras e Ciências Humanas, Universidade de São Paulo. São Paulo, 2007. Disponível em: < www.teses.usp.br/teses $/ \ldots / 8 / 8137 / \ldots /$ TESE_VICENTE_CONTADOR.pdf>.

CORAGGIO, J. Hacia una revisión de la teoría de los polos de desarrollo. EURE, v.2, n.4, p.25-39, 1972.

CYSNE, R, A economia brasileira no período militar. In: DILLON SOARES, G.; D'ARAUJO, M. C. (Org.) 21 anos de regime militar. Rio de Janeiro: Fundação Getulio Vargas, 1994. p.232-270.

DELRIO, W. Memorias de expropiación. Sometimiento e incorporación indígena en la Patagonia (1872-1943). Bernal: Universidad Nacional de Quilmes, 2005.

DRAIBE, S. As políticas sociais do regime militar brasileiro: 1964-84. In: DILLON SOARES, G.; D'ARAUJO, M. (Org.) 21 anos de regime militar. Rio de Janeiro: Fundação Getulio Vargas, 1994. p.271-309.

FARIAS DE MOURA, L.; SCHOR, T.; ALDEMIR DE OLIVEIRA, J. As politicas públicas habitacionais em Manaus $(A M)$ e a orientação da expansão urbana. UFAm, 2011. Disponível em: <http://xiisimpurb201l.com.br/app/web/arq/trabalhos/ e8f3163c4507528f6cc5abbb44875690.pdf>. 
FERNANDES, F. A revolução burguesa no Brasil. Rio de Janeiro: Zahar, 1975.

FONSECA GADELHA, R. Conquista e ocupação da Amazônia: a fronteira Norte do Brasil. Estudos Avançados, São Paulo, v.16, n.45, p.63-81, 2002.

GATICA, M. Trelew, ¿un polo de desarrollo y modernización?. In: Actas IV Jornadas de Historia. Caleta Olivia: UNPA, 1998.

. ¿Exilio, migración, destierro? Trabajadores chilenos en el noreste de Chubut (1973-2010). Buenos Aires: Prometeo, 2013.

GATICA, M. et al. Patagonia: desarrollo y neoliberalismo. Buenos Aires: Imago Mundi, 2005.

GÓMEZ LENDE, S. Del medio natural al medio técnico científico-informacional. Una síntesis geográfica... GEOCALLI Cuadernos de Geografía, Guadalajara, año 8, n.15, 2007. Disponível em: <http://ffyl.uncu.edu.ar/IMG/pdf/prom_ind_TdelF.pdf>.

GRIGERA, J. Promoción industrial en Argentina: el caso de Tierra del Fuego (19702007). In: Actas XIII Jornadas Interescuelas Departamento de Historia. Catamarca: UNCat, 2011.

HEALEY, M. El interior en disputa: proyectos de desarrollo y movimientos de protesta en las regiones extra-pampeanas. In: JAMES, D. Violencia, Proscripción y Autoritarismo, Nueva Historia Argentina. Buenos Aires: Sudamericana, 2003.

HOBSBAWM, E. Historia del Siglo XX. Buenos Aires: Crítica, 1999.

IBARRA, H. Patagonia Sur. La construcción interrumpida de un proceso de desarrollo regional. Trelew: Depto. Historia, FHCS, UNPSJB, 1997. mimeo.

KATZ, J. Una nueva visita a la teoría del desarrollo económico. Santiago de Chile: Cepal, 2008.

KOHLHEPP, G. Conflitos de interesse no ordenamento territorial da Amazônia. Estudos Avançados, São Paulo, v.16, n.45, p.37-62, 2002.

LAMBERT, J. Os dois Brasis. São Paulo: Companhia Editora Nacional, 1976.

MUSSI, E.; RODRÍGUEZ CYBULSKI, V. Una industria fría, fría... Las maquilas de segunda en Tierra del Fuego. El Aromo, Buenos Aires, n.63, nov./dic. 2011. Disponível em: <http://www.razonyrevolucion.org/ryr/index.php?>.

OLIVEIRA DE ANDRADE, A.; FERREIRA COELHO, R. O perfil ocupacional do trabalhador da indústria de eletroeletrônicos. In: VII SEMINÁRIO TRABALHO, 2010. Disponível em: <http://www.estudosdotrabalho.org/anais-vii-7-seminario-trabalho-ret-2010.pdf>.

OLIVEIRA, E. As forcas armadas: política e ideologia no Brasil (1964-1969). Petrópolis: Vozes, 1976.

ORNELAS DELGADO, J. Volver al desarrollo. Problemas del Desarrollo, México, v.43, n.168, p.7-35, enero-marzo 2012.

PEREIRA DA COSTA, D.; ALDEMIR DE OLIVEIRA, J. Conjuntos habitacionais e a expansão urbana de Manaus... Mercator - Revista de Geografia da UFC, ano 6, n.11, p.33-48, 2007.

PÉREZ ÁLVAREZ, G. Patagonia, conflictividad social y neoliberalismo. El noreste de Chubut (1990-2005). Buenos Aires: Imago Mundi, 2013. 
PERRÉN, J. 1985: Argentina Potencia Mundial. Desarrollismo y proyecciones demográficas en la prensa del sesquicentenário. Quinto Sol, Santa Rosa, n.12, 2008.

PERRÉN, J.; PÉREZ ÁLVAREZ. Las “nuevas” provincias como problema historiográfico. Una aproximación a los casos patagónicos (1958-1991). Revista Pasado Por-Venir, Trelew, n.5, p.75-101, 2011.

PERROUX, F. Notes sur la notion de pole de croissance. Economie Appliquée, Paris, n.8, janvier-juin, 1955.

PINTO, L. F. Três reflexões sobre segurança nacional na Amazônia. Estudos Avançados, São Paulo, v.16, n.46, p.131-41, 2002.

PRADO JUNIOR, C. Histórica econômica do Brasil. São Paulo: Brasiliense, 1959.

PUGA FERREIRA, S. M.; BOTELHO, L. O emprego industrial na Região Norte: o caso do Polo Industrial de Manaus. Estudos Avançados, São Paulo, v.28, n.81, maio/ago. 2014. Disponível em: <http://www.scielo.br/scielo.php?pid=S0103-40142014000200>.

ROUGIER, M. Estado y empresarios de la industria del aluminio en la Argentina. El caso Aluar. Buenos Aires: Editorial UNQ, 2011.

SALAZAR, J. P. O abrigo dos deserdados. Estudo sobre a remoção dos moradores da Cidade Flutuante e os reflexos da Zona Franca na habitação da população de baixa renda em Manaus. São Paulo, 1985. Dissertação (Mestrado) - Faculdade de Filosofia, Letras e Ciências Humanas, Universidade de São Paulo. São Paulo, 1985.

O novo proletariado industrial de Manaus e as transformações sociais possíveis: estudo de um grupo de operários. São Paulo, 1992. Tese (Doutorado) - Faculdade de Filosofia, Letras e Ciências Humanas, Universidade de São Paulo. São Paulo, 1992.

SCHORR, M.; PORCELLI, L. La industria electrónica de consumo en Tierra del Fuego. Régimen promocional, perfil de especialización y alternativas de desarrollo sectorial en la posconvertibilidad. Documentos de Investigación Social, Buenos Aires, n.26, 2014.

SCHVARZER, J. Promoción industrial en Argentina. Características, evolución y resultados. Buenos Aires: Documentos del CISEA, 1986.

SERÁFICO, J.; SERÁFICO, M. A Zona Franca de Manaus e o capitalismo no Brasil. Estudos Avançados, São Paulo, v.19, n.54, p. 99-113, 2005

SINGER, P. A crise do “milagre”. São Paulo: Paz e Terra, 1982.

STAVENHAGEN, R. Siete tesis equivocadas sobre América Latina. Sociología y Subdesarrollo, México, p.15-84, 1981. Disponível em: <http://pensamientolatinoamericanounmdp.files.wordpress.com/2011/10.pdf>.

TRINDADE, H. O radicalismo militar em 64 e a nova tentação fascista. In: DILLON SOARES, G.; D'ARAUJO, M. (Org.) 21 anos de regime militar. Rio de Janeiro: Fundação Getulio Vargas, 1994. p.123-41.

VIDAL, G.; GUILLÉN, A. (Comp.) Repensar la teoría del desarrollo en un contexto de globalización. Buenos Aires: Clacso, 2008.

VIRGílio, A. Polo Industrial de Manaus: ideia vitoriosa que não permite retrocesso. Brasília: Senado Federal, Secretaria Especial de Editoração e Publicações, 2006.

WIEDEMANN, L. F. (Coord.) Brasil realidade e desenvolvimento. São Paulo: Sugestões Literárias, 1977. 
RESUMO - Os planos de desenvolvimento formulados pelo governo argentino para a Patagônia argentina tem evidentes semelhanças com os projetos que o Estado federal do Brasil propôs para a Amazônia brasileira. Os dois casos são, no fundamental, planos de desenvolvimento industrial subsidiados pelo Estado nacional. A comparação entre as duas regiões se faz evidente em suas características comuns de serem ricas em recursos naturais cobiçados por potências estrangeiras, em seem definidas por seus governos nacionais como áreas "subdesenvolvidas", e por terem uma baixíssima densidade populacional (desde a ideia de que elas eram "regiões vazias"). Procuramos debater a relação entre a história dessa região da Argentina com os projetos de desenvolvimento promovidos pelo governo federal do Brasil para a Amazônia. Registramos a fonte autoritária de ambos os projetos, o peso da doutrina de segurança nacional em suas formulações e a incidência que em eles tiveram as populações das regiões mencionadas.

PALAVRAS-CHAVES: Amazônia, Patagônia, Desenvolvimento, Soberania.

ABSTRACT - The development plans formulated by the Argentine government for Patagonia has obvious similarities with the projects that the Brazilian State proposed for Amazonia. Both are, essentially, industrial development plans subsidized by the national State. A comparison between the two regions makes their common characteristics clear: both are rich in natural resources coveted by foreign powers, are defined by their national government as "underdeveloped" areas, and have very low population density (since the notion that they were "empty regions"). We discuss the relationship between the history of this region of Argentina and the development projects promoted by the federal government of Brazil for Amazonia. We also register the authoritarian source of both projects, the weight of the doctrine of national security doctrine in their formulation, and their effect on the populations of those regions.

KEYWORDS: Amazonia, Patagonia, Development, Sovereignty.

Gonzalo Pérez Álvarez é professor na Universidade Nacional da Patagônia San Juan Bosco, Província de Chubut, Argentina. Conicet. @ - gonzaloperezalvarez@yahoo.com Recebido em 10.11.2014 e aceito em 29.07.2015.

${ }^{\text {I } U n i v e r s i d a d ~ N a c i o n a l ~ d e ~ l a ~ P a t a g o n i a ~ S a n ~ J u a n ~ B o s c o, ~ P r o v i n c i a ~ d e l ~ C h u b u t, ~ A r g e n t i n a . ~}$ 